\title{
Etiology of acute otitis media and phenotypic-molecular characterization of Streptococcus pneumoniae isolated from children in Liuzhou, China
}

\author{
Jinjian $\mathrm{Fu}^{1 \dagger}$, Ling $\mathrm{Li}^{2+}$, Zhuoxin Liang ${ }^{3+}$, Shaolin $\mathrm{Xu}^{1+}$, Nan Lin ${ }^{4 \dagger}$, Peixu Qin ${ }^{1}$, Xiaohua Ye ${ }^{2^{*}}$ and Eric McGrath ${ }^{5,6}$
}

\begin{abstract}
Background: The etiology and epidemiology of acute otitis media (AOM) are poorly understood in China. This study aimed to describe the etiology of AOM and the phenotypic and molecular characteristics of AOM-causing Streptococcus pneumoniae (S.pneumoniae) recovered from Chinese children.

Methods: A retrospective study was conducted to enrol patients younger than 18 years diagnosed as AOM. Middle ear fluid specimens were collected then cultured for bacterial pathogens. All S.pneumoniae isolates were tested for antibiotic susceptibility, serotypes, virulence genes, antibiotic resistant determinants and sequence types.

Results: The dominant otopathogen among AOM children was S.pneumoniae (54.4\%). Among S.pneumoniae isolates, there were $97.3,97.3$ and $75.7 \%$ isolates resistant to erythromycin, tetracycline and trimethoprimsulfamethoxazole, respectively. There was $72.8 \%$ S.pneumoniae with multidrug resistance. The dominant sequence types (STs) were ST271 and ST320, whereas the prevailing serotypes were 19F and 19A. The 7-valent and 13-valent pneumococcal conjugate vaccine (PCV) coverage among AOM children were 73.0 and $94.6 \%$, respectively. Additionally, we found that CC271 expressed more of mef(A/E) $(P<0.001)$, pspA $(P=0.022)$ and $\operatorname{sip} A(P<0.001)$ than non-CC271 isolates.
\end{abstract}

Conclusion: The high prevalence of international multidrug-resistant clone (Taiwan ${ }^{19 F}$-14) in China necessitates continued dedication to expand PCV13 immunization and better control of antibiotic use in China.

Keywords: Acute otitis media, Streptococcus pneumoniae, Children, Vaccine, Molecular characteristics

\section{Background}

Acute otitis media (AOM) is one of the most frequently encountered bacterial infections and the leading cause of medical visits and antibiotic prescription in children worldwide [1, 2]. Among the pathogens involved in this infection, Streptococcus pneumoniae (S.pneumoniae) and Haemophilus influenzae (H.influenzae) are the principal bacterial otopathogens that account for up to $60-80 \%$ of microbiologically confirmed AOM [3, 4]. Concerns have been rising about the major role of S.pneumoniae in

\footnotetext{
*Correspondence: smalltomato@163.com

${ }^{\dagger}$ Jinjian Fu, Ling Li, Zhuoxin Liang, Shaolin Xu and Nan Lin contributed equally to this work.

${ }^{2}$ School of Public Health, Guangdong Pharmaceutical University, 283\#

Jianghai Dadao, Haizhu District, Guangzhou 510310, China

Full list of author information is available at the end of the article
}

AOM etiology, which coincides with growing antibiotic resistance rates among S.pneumoniae isolates. In China, the rate of penicillin-nonsusceptible S.pneumoniae (PNSP) ranges from $11.5-39.4 \%[5,6]$. The Asian Network for Surveillance of Resistant Pathogens (ANSORP) reported that, in China, the rate of resistance to erythromycin was as high as $96.4 \%$, whilst multidrug resistance was $83.3 \%$, which rank China highest among the 11 enrolled Asian countries surveyed [7].

Increasing rates of resistance of S.pneumoniae to commonly used antibiotics highlights the increased urgency for use of vaccines for controlling pneumococcal diseases. The heptavalent pneumococcal polysaccharide conjugate vaccine (PCV7) has had a dramatic effect on reducing the disease burden of pneumococcal diseases

C The Author(s). 2019 Open Access This article is distributed under the terms of the Creative Commons Attribution 4.0 International License (http://creativecommons.org/licenses/by/4.0/), which permits unrestricted use, distribution, and 
globally, including AOM $[8,9]$. The increased prevalence of pneumococcal diseases caused by non-vaccine serotypes, especially serotype 19A from an emerging clonal complex (CC) 320, has been well documented in the post PCV7 era [10, 11]. PCV7 has been available as a self-paid vaccine in mainland China since August 2008, but immunization rates were less than $10 \%$ in published studies $[12,13]$.

Despite a well-developed knowledge base of S.pneumoniae worldwide, in China, little has been reported on the microbial etiology of AOM and phenotypic-molecular characteristics of S.pneumoniae, the predominant otopathogen. Therefore, we conducted this study in China to investigate the bacterial etiology and characterize pneumococcal isolates obtained from children with AOM. Phenotypic and genotypic characteristics of the pneumococcal isolates from AOM patients, including antimicrobial susceptibility, serotypes, multilocus sequence typing (MLST) profiles, and virulence genes of $S$. pneumoniae were also investigated.

\section{Methods}

\section{Patients and isolates}

This study was approved by the Ethics Committee of Liuzhou Maternity and Child Healthcare Hospital, and was performed in accordance with the approved guidelines. Before enrolment of a child into this study, written informed consent was obtained from parents or legal guardians on behalf of the children involved in the study for collection of information and samples.

This retrospective study was conducted from January 1st 2016 to June 30th 2016 in the otolaryngology clinic of Liuzhou Maternity and Child Health Care Hospital. Children aged younger than 18 years old, with no prior $\mathrm{AOM}$ at the time of enrolment, were enrolled in this study. AOM was diagnosed by the otolaryngologist or pediatrician after otoscopic examination of the ear drum, confirmation of acute onset of symptoms lasting $\leq 7$ days consistent with $\mathrm{AOM}$ and accompanied by one or more of the following symptoms: substantial bulging of the tympanic membrane, marked redness of the tympanic membrane, and a cloudy or purulent effusion was observed.

Middle ear fluid specimens were obtained by either tympanocentesis or collection of pus from draining ears and were immediately delivered to the clinical microbiology laboratory for culture. The specimens were plated on Colombia blood agar with 5\% sheep blood and Chocolate agar and placed in $35^{\circ} \mathrm{C}, 5 \% \mathrm{CO}_{2}$ incubated for $24 \mathrm{~h}$ to 48 h. All agars were purchased from Autobio (Henan, China). S.pneumoniae was identified by typical alpha haemolysis and draftsman colonies on the blood agar plate together with optochin test and bile solubility test. H.influenzae was identified by growth requirements for factors $\mathrm{V}$ and
$\mathrm{X}$. The disk of optochin, $\mathrm{X}, \mathrm{V}$ and $\mathrm{X}+\mathrm{V}$ were purchased from OXOID (Hampshire, England). The suspected isolates were confirmed by the VITEK 2 Gram Positive Card (Streptococcus pneumoniae, Staphylococcus aureus, Streptococcus pyogenes), Gram Negative Card (Pseudomonas aeruginosa), and Neisseria-Haemophilus Card (Haemophilus influenzae) using VITEK 2 compact automatic microbial analysis system (Biomérieux, Marcyl' Etoile, France). Chromogenic Agar medium was used for Candida species identification (Biomérieux) and API 20C AuX (Biomérieux) was used for confirmation. In this study, we only focused on the epidemiology and phenotypic-molecular characterization of S. pneumoniae. The pneumococcal isolates were stored at $-80{ }^{\circ} \mathrm{C}$ in $10 \%$ glycerol-brain heart infusion broth with $50 \%$ sheep blood.

\section{Antibiotic susceptibility test}

The antibiotic susceptibility of S.pneumoniae isolates were determined by the minimum inhibitory concentration with the VITEK 2 Gram Positive Susceptibility Card-AST-GP68 using VITEK2 systems. Definitions of antibiotic susceptibility were based on the Clinical and Laboratory Antimicrobial Standards Institute (CLSI) 2016 criteria [14]. Current CLSI susceptible, intermediate, resistant (respectively) breakpoints for parenteral penicillin $(2 \mu \mathrm{g} / \mathrm{ml}, 4 \mu \mathrm{g} / \mathrm{ml}, 8 \mu \mathrm{g} / \mathrm{ml}$; nonmeningitis $)$, oral penicillin $(0.06 \mu \mathrm{g} / \mathrm{ml}, 1 \mu \mathrm{g} / \mathrm{ml}, 2 \mu \mathrm{g} / \mathrm{ml})$, cefotaxime $(1 \mu \mathrm{g} / \mathrm{ml}, 2 \mu \mathrm{g} / \mathrm{ml}, 4 \mu \mathrm{g} / \mathrm{ml}$; nonmeningitis), erythromycin $(0.25 \mu \mathrm{g} / \mathrm{ml}, 0.5 \mu \mathrm{g} / \mathrm{ml}, 1 \mu \mathrm{g} / \mathrm{ml})$, and levofloxacin $(2 \mu \mathrm{g} /$ $\mathrm{ml}, 4 \mu \mathrm{g} / \mathrm{ml}, 8 \mu \mathrm{g} / \mathrm{ml})$, tetracycline $(1 \mu \mathrm{g} / \mathrm{ml}, 2 \mu \mathrm{g} / \mathrm{ml}$, $4 \mu \mathrm{g} / \mathrm{ml})$, trimethoprim -sulfamethoxazole $(0.5 / 0.95 \mu \mathrm{g} /$ $\mathrm{ml}, 2 / 38 \mu \mathrm{g} / \mathrm{ml}, 4 / 76 \mu \mathrm{g} / \mathrm{ml}$ ) were considered. The CLSI QA and QC guidelines were followed for antibiotic susceptibility testing together with $S$. pneumoniae ATC C49619 as the quality control strain. Isolates non-susceptible to at least 3 antibiotic classes were defined as multidrug-resistant $S$. pneumoniae.

\section{DNA extraction}

Chromosomal DNA was extracted from the overnight subculture of S.pneumoniae isolates by using Biospin Bacteria Genomic DNA Extraction Kit (Bioer Ltd., Hangzhou, China) according to the manufacturer's instructions.

\section{Serotyping}

Pneumococcal serotyping was performed using multiplex polymerase chain reaction (m-PCR) methods as described in a previous study [15]. Thirty-six different serotypes were determined by 8 sequential m-PCR reactions and the method used to distinguish serotypes $6 \mathrm{~A} /$ $6 \mathrm{~B}$ was as reported previously [6]. 
Detection of antibiotic-resistant genes

The macrolide-resistant genes $\operatorname{erm}(\mathrm{A}), \operatorname{erm}(\mathrm{B})$ and mef(A/E) were amplified by PCR methods for all erythromycin-resistant isolates [16]. The tet $(\mathrm{K})$, tet $(\mathrm{L})$ and tet $(\mathrm{O})$ genes were amplified by PCR for all tetracycline-resistant isolates using the primers and PCR conditions as previously described [17]. All the PCR products were visualized by $1.5 \%$ agarose gel electrophoresis and gold-view staining.

\section{Detection of virulence genes}

Detection of virulence genes ( $p l y, p a s A, l y t A, p s p A)$ and pili genes ( $r l r A$ for PI-1and $\operatorname{sip} A$ for PI-2) of pneumococcal isolates were amplified using PCR and all primers, PCR reactions and conditions used were as previously described [17]. The $100 \mathrm{bp}$ plus DNA ladder marker (Takara, China) was used for molecular weight reference.

\section{Multilocus sequence typing}

Sequence types (STs) of pneumococcal isolates were determined using the multilocus sequence typing (MLST) technique. Internal fragments of 7 housekeeping genes (aroE, gdh, gki, recP, spi, xpt, $d d l$ ) were amplified from chromosomal DNA by PCR [18]. Allelic profiles and STs were assigned by comparison with pneumococcal MLST database (https://pubmlst.org/spneumoniae), and clonal complexes (CCs) were determined using the eBURST algorithm. The definition of a clonal complex is a group in which every strain shares at least five identical alleles out of seven with at least one other genotype in the group [19].

\section{Statistical analysis}

Data were analyzed using descriptive statistics and Pearson's chi-squared $\left(\chi^{2}\right)$ test or Fisher exact test. A two-sided $P$-value of less than 0.05 was considered as being of statistical significance. All statistical analyses were conducted using SPSS version 20.0 (SPSS Inc. Chicago, Il, USA). PHYLOViZ method (http://www.phyloviz.net) was used to demonstrate the relationship of serotypes and MLST.

\section{Results}

\section{Microbiology of AOM}

Seventy-nine patients were enrolled during the study period. Eighty-four samples were collected from 79 patients, 68 samples from 68 patients were culture positive. The predominant pathogen was S.pneumoniae (37 isolates), followed by H.influenzae (12 isolates), Staphylococcus aureus (7 isolates), Pseudomonas aeruginosa (5 isolates), Streptococcus pyogenes (4 isolates) and Candida albicans (3 isolates). The demographic information of children with AOM is shown in Table 1. Seventy-four of the 79 children with AOM (93.7\%) were less than 2 years
Table 1 The demographic information of children with AOM

\begin{tabular}{llllll}
\hline Characteristic & AOM & & \multicolumn{2}{c}{ S. pneumoniae positive } \\
& $n$ & $\%$ & & $n$ & $\%$ \\
\hline Gender & & & & \\
Male & 46 & 58.2 & & 23 & 62.2 \\
$\quad$ Female & 33 & 41.8 & & 14 & 37.8 \\
Age (months) & & & & \\
11 & 20 & 25.3 & & 12 & 32.4 \\
$12-23$ & 27 & 34.2 & & 11 & 29.7 \\
$24-59$ & 27 & 34.2 & & 14 & 37.8 \\
$\geq 60$ & 5 & 6.3 & & 0 & 0.0 \\
\hline AOM acute otitis media & & &
\end{tabular}

old, and the majority of the patients were male (58.2\%). All 37 children experiencing pneumococcal AOM were less than 2 years old, whilst $62.2 \%$ were male.

\section{Antibiotic susceptibility of S. pneumoniae}

In pneumococcal isolates, no isolate was resistant to parenteral penicillin, but the intermediate and resistant rates reached 59.5\% (22/37) and 27.0\% (10/37), respectively, based on the oral breakpoints. The non-susceptibility rates were low for levofloxacin (2.7\%) and chloramphenicol (8.1\%), but high for erythromycin (100.0\%), tetracycline (97.3\%) and trimethoprim-sul famethoxazole $(83.8 \%)$ (Table 2 ). The multidrug-resistant rate of pneumococcal isolates was $72.8 \%$. The most common multidrug-resistant patterns were non-susceptibility to erythromycin/tetracycline/trimethopri m-sulfamethoxazole (59.5\%), erythromycin/tetracycline/trimethoprim-sulfamethoxazole/chloramphenicol (8.1\%) and erythromycin/tetracycline/trimethoprim-sulfamethoxazole/cefotaxime (5.4\%).

\section{Serotyping, vaccine coverage and sequence types of $S$. pneumoniae}

Among the 37 S.pneumoniae isolates, the predominant serotypes were 19F (62.2\%) and 19A (18.9\%), accounting for $81.1 \%$ of all the isolates. The pneumococcal vaccine coverage rate for the pneumococcal isolates was $73.0 \%$ for PCV7, but high at $94.6 \%$ for PCV13 (Fig. 1). All 36 S.pneumoniae isolates were successfully typed by MLST, only one isolate, serotype 19F, failed to sequence. Among the $8 \mathrm{STs}$ identified, the most common STs were ST271 $(n=19,51.4 \%)$ and ST320 $(n=9,24.3 \%)$, with the majority of ST271 and ST320 isolates serotyped as $19 \mathrm{~F}$ and 19A, respectively (Fig. 2). The eBURST analysis revealed $1 \mathrm{CC}$ and 6 singletons containing 75.7 and $21.6 \%$ of the isolates, respectively, with the predominant CC271 including 28 isolates (75.7\%). 
Table 2 Antimicrobial susceptibility of S. pneumoniae isolated from children with AOM

\begin{tabular}{|c|c|c|c|c|c|}
\hline Antibiotic & Susceptible n (\%) & Intermediate n (\%) & Resistant n(\%) & $\mathrm{MIC}_{50}(\mu \mathrm{g} / \mathrm{mL})$ & $\mathrm{MIC}_{90}(\mu \mathrm{g} / \mathrm{mL})$ \\
\hline Penicillin Parenteral $^{a}$ & $36(97.3)$ & $1(2.7)$ & $0(0.0)$ & 0.15 & 1 \\
\hline Penicillin Oral & $5(13.5)$ & $22(59.5)$ & $10(27.0)$ & 0.15 & 1 \\
\hline Vancomycin & $37(100.0)$ & $0(0.0)$ & $0(0.0)$ & 0.5 & 0.5 \\
\hline Erythromycin & $0(0.0)$ & $1(2.7)$ & $36(97.3)$ & 1 & 2 \\
\hline Levofloxacin & $36(97.3)$ & $1(2.7)$ & $0(0.0)$ & 0.5 & 1 \\
\hline Tetracycline & $1(2.7)$ & $0(0.0)$ & $36(97.3)$ & 4 & 16 \\
\hline Trimethoprim-sulfamethoxazole & $6(16.2)$ & $3(8.1)$ & $28(75.7)$ & $0.5 / 0.95$ & $0.5 / 0.95$ \\
\hline Linezolid & $37(100.0)$ & $0(0.0)$ & $0(0.0)$ & 0.5 & 0.5 \\
\hline Chloramphenicol & $34(91.9)$ & $0(0.0)$ & $3(8.1)$ & 2 & 4 \\
\hline Cefotaxime $^{a}$ & $31(83.8)$ & $4(10.8)$ & $2(5.4)$ & 1 & 2 \\
\hline
\end{tabular}

$A O M$, acute otitis media

${ }^{\mathrm{a}} 2016$ CLSI breakpoints were considered for nonmeningitis

\section{Antibiotic resistance genes and virulence genes of $S$.} pneumoniae

Among the 37 pneumococcal isolates (Table 3), 94.6\% (35 isolates) carried erm(B) gene, 64.9\% (24 isolates) carried $m e f(\mathrm{~A} / \mathrm{E})$ gene, $94.6 \%$ (35 isolates) carried tet $(\mathrm{M})$ gene, and only 1 isolate carried tet $(\mathrm{O})$ gene. Notably, about $94.6 \%$ of S.pneumoniae isolates were co-resistant to tetracycline and erythromycin, carrying both $\operatorname{erm}(\mathrm{B})$ and tet(M) genes, whilst none of the 37 isolates contained macrolide or tetracycline resistance genes, such as $\operatorname{erm}(\mathrm{A})$, tet $(\mathrm{K})$ or tet $(\mathrm{L})$. Tetracycline phenotypic resistance results showed that over $91.9 \%$ (34/37) of isolates carried tet $(\mathrm{M})$ gene. In comparison, the macrolide phenotypic resistance results, showed $94.6 \%(35 / 37)$ of isolates carried erm(B) gene, while only $62.2 \%(23 / 37)$ carried mef(A/E) gene, indicating good correlation between phenotypic-genotypic results in terms of tetracycline and erythromycin resistance. In all of the isolates, 97.3\% (36 isolates) carried both pneumococcal virulence genes $l y t A$ and $p l y$, and $83.8 \%$ (31 isolates) carried pspA gene. The $r \operatorname{lr} A$ gene was identified in 22 of 37 (59.5\%) isolates, and $\operatorname{sip} A$ was detected in $67.6 \%$ (25 isolates) of the pneumococcal isolates.

\section{Relations between ST types, serotypes, and resistance- virulence characteristics}

All the serotype 19A isolates belonged to ST320 (Table 3). Overall, 73.3\% of serogroup 19 harbored mef(A/E), while $14.3 \%$ of the non-serotype 19 harbored $m e f(\mathrm{~A} / \mathrm{E})(P=$ 0.007). The same difference was observed in $\operatorname{sip} A$ ( $P$ $<0.001$ ). Up to $80 \%$ (22 isolates) of CC271 clones expressed $m e f(\mathrm{~A} / \mathrm{E})$, and only $11.1 \%$ of other isolates expressed $m e f(\mathrm{~A} / \mathrm{E})$, indicating significant difference between two groups $(P<0.001)$. Similar significant differences were observed in the carriage of $p s p A(P=0.022)$ and $\operatorname{sip} A(P<$ 0.001) genes expressed in CC271 clones and other isolates. As to antibiotic resistance genes and pneumococcal virulence genes, we observed that ST271 expressed more of

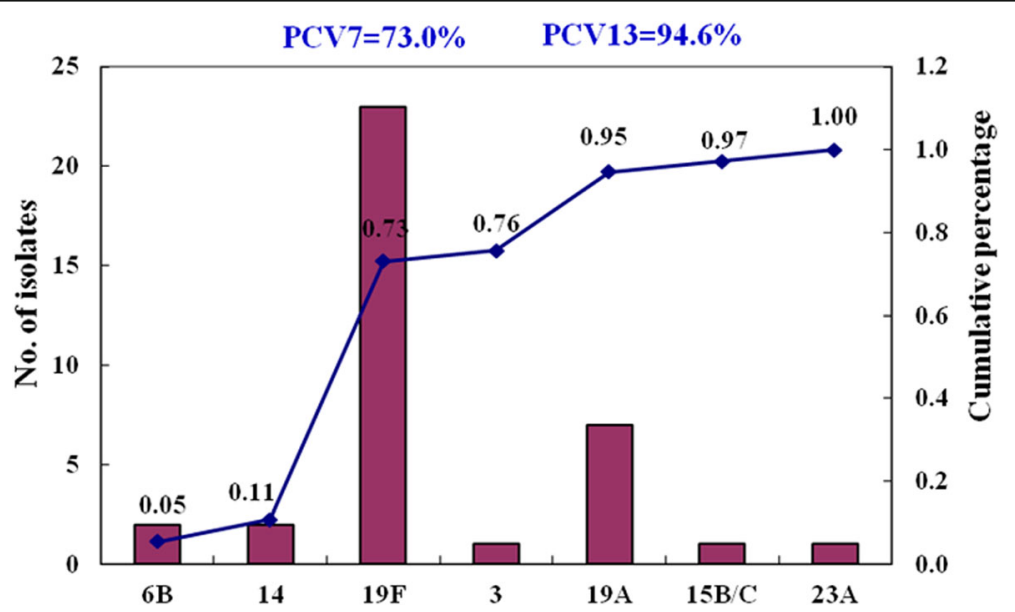

Fig. 1 Serotype distribution in 37 S.pneumoniae isolates recovered from AOM patients (PCV7 includes serotypes 4, 6B, 9V, 14, 18C, 19F, and 23F; PCV13 includes serotypes 1, 3, 4, 5, 6A, 6B, 7F, 9V, 14, 18C, 19A, 19F, and 23F) 


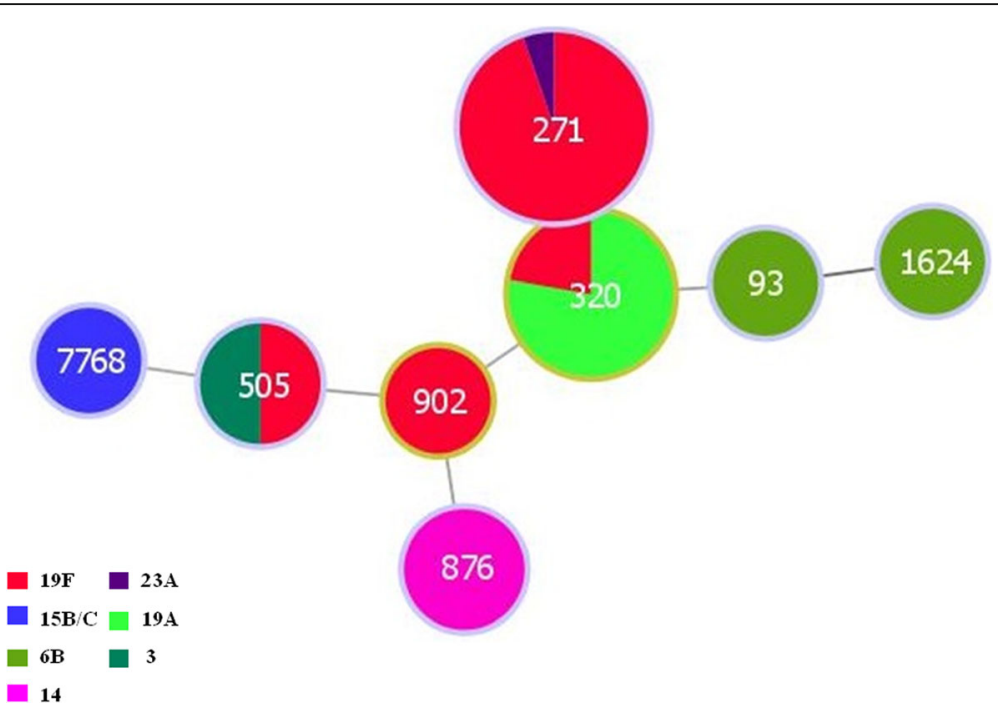

Fig. 2 The relationship between serotype and genotype of pneumococci recovered from AOM patients

mef(A/E) $(P=0.004)$ and $\operatorname{sip} A(P=0.001)$ than non-ST271 isolates.

\section{Discussion}

AOM is a common upper respiratory tract infection among children younger than 5 years old. The monitoring of etiology of AOM, antibiotic resistance and the molecular background of AOM-causing S.pneumoniae provides opportunities to identify changes in the predominant bacteria and the impact of changing antibiotic resistance and prevalence of virulence genes within these bacteria that may result from environmental selection pressures such as pneumococcal immunization and antibiotic use. In this retrospective study, we found that S.pneumoniae was the most prevalent pathogen causing for $\mathrm{AOM}$ in the recruited children and was isolated from $46.8 \%$ of the cohort. The high proportion of the pneumococcal isolates resistant to erythromycin, tetracycline and trimethoprim-sulfamethoxazole (59.5\%) is consistent with the Suzhou study of nasopharyngral isolates [20]. Interestingly, the proportion of pneumococcal isolates that were resistant to penicillin, was inconsistent with previous reports from China that demonstrated a high prevalence of resistance to penicillin $[6,20]$. This inconsistency may be explained by the prescribing pattern in Liuzhou, which uses macrolide antibiotics such

Table 3 Molecular characteristics of S. pneumoniae isolated from children with AOM

\begin{tabular}{|c|c|c|c|c|c|c|c|c|}
\hline \multirow[t]{2}{*}{ ST,serotype (n) } & \multicolumn{3}{|c|}{ Resistance genes n(\%) } & \multicolumn{5}{|c|}{ Virulence genes n(\%) } \\
\hline & erm(B) & mef(A/E) & $\operatorname{tet}(\mathrm{M})$ & ply & lytA & $p s p A$ & $r \mid r A$ & $\operatorname{sip} A$ \\
\hline ST271,19F(18) & $17(45.9)$ & $15(40.5)$ & $18(48.6)$ & $18(48.6)$ & $18(48.6)$ & $17(45.9)$ & $13(35.1)$ & $17(45.9)$ \\
\hline ST271,23A(1) & $1(2.7)$ & $1(2.7)$ & $1(2.7)$ & $1(2.7)$ & $1(2.7)$ & $1(2.7)$ & $0(0.0)$ & $0(0.0)$ \\
\hline ST320,19F(2) & $1(2.7)$ & $1(2.7)$ & $1(2.7)$ & $2(5.4)$ & $2(5.4)$ & $2(5.4)$ & $2(5.4)$ & $2(5.4)$ \\
\hline ST320,19A(7) & $7(18.9)$ & $5(13.5)$ & $7(18.9)$ & $7(18.9)$ & $7(18.9)$ & $6(16.2)$ & $4(10.8)$ & $5(13.5)$ \\
\hline ST505,3 (1) & $1(2.7)$ & $0(0.0)$ & $1(2.7)$ & $1(2.7)$ & $1(2.7)$ & $0(0.0)$ & $0(0.0)$ & $0(0.0)$ \\
\hline ST505,19F(1) & $1(2.7)$ & $0(0.0)$ & $1(2.7)$ & $1(2.7)$ & $1(2.7)$ & $0(0.0)$ & $0(0.0)$ & $0(0.0)$ \\
\hline ST876,14 (2) & $2(5.4)$ & $0(0.0)$ & $2(5.4)$ & $2(5.4)$ & $2(5.4)$ & $2(5.4)$ & $0(0.0)$ & $0(0.0)$ \\
\hline ST902,19F(1) & $1(2.7)$ & $1(2.7)$ & $1(2.7)$ & $1(2.7)$ & $1(2.7)$ & $0(0.0)$ & $1(2.7)$ & $1(2.7)$ \\
\hline ST1624,6B(1) & $1(2.7)$ & $0(0.0)$ & $1(2.7)$ & $1(2.7)$ & $1(2.7)$ & $1(2.7)$ & $1(2.7)$ & $0(0.0)$ \\
\hline ST7768,15B/C(1) & $1(2.7)$ & $0(0.0)$ & $1(2.7)$ & $1(2.7)$ & $1(2.7)$ & $1(2.7)$ & $1(2.7)$ & $0(0.0)$ \\
\hline ST93,6B(1) & $1(2.7)$ & $0(0.0)$ & $1(2.7)$ & $1(2.7)$ & $1(2.7)$ & $1(2.7)$ & $0(0.0)$ & $0(0.0)$ \\
\hline Untypeable,19F(1) & $1(2.7)$ & $0(0.0)$ & $0(0.0)$ & $0(0.0)$ & $0(0.0)$ & $0(0.0)$ & $0(0.0)$ & $0(0.0)$ \\
\hline Total & 35 (94.6) & $23(62.2)$ & 35 (94.6) & $36(97.3)$ & $36(97.3)$ & $31(83.8)$ & $22(59.5)$ & $25(67.6)$ \\
\hline
\end{tabular}

NOTE. Values are number of isolates

AOM, acute otitis media 
as erythromycin and azithromycin, not penicillin, as the first option prescription for pediatric patients. The second reason may be that the isolates we collected were from middle ear fluid of pediatric patients with AOM, which were reported more frequently in the community. There was report that the S.pneumoniae isolates were more susceptible to penicillin within the community than in the medical places [21], which may explain the inconsistency of our results from other reports collected isolates from hospitalized children with a high prevalence of resistance to penicillin [6].

It was reported that the resistance of S.pneumoniae to the third-generation cephalosporin was increasing in some area of China. For example, in Suzhou, among the S.pneumoniae isolates collected from the children with AOM, the penicillin resistant S.pneumoniae (PRSP) was $10.2 \%$, while the resistance rate of cefotaxime (CTX) was 34.3\% [20]. Among the 58 S.pneumoniae CC271 clones of the serotype 19F collected from children with non-meningitis in Beijing, the non-susceptible rate to ceftriaxone was $96.4 \%$, while only $8.6 \%$ isolates was penicillin non-susceptible S.pneumoniae (PNSP) [22]. In our study, only 1 of the S.pneumoniae isolates was determined as PNSP, but as many as $16.2 \%(6 / 37)$ of isolates were determined as CTX non-susceptible S.pneumoniae (using non-meningitis breakpoints based on the CLSI criteria [14]), which was consistent with the previous reports $[5,6,20,22]$. Interestingly, all 7 of these isolates are serotype 19F, ST271clone. These findings are supported by a report from Ip $\mathrm{M}$ et al. [23] which observed that in Hongkong 2011, the rates of PNSP and CTX non-susceptibility were 23.3 and $30.3 \%$ respectively but that all of the CTX resistant isolates were attributed to the single serotype 19F, CC271, with only $25.3 \%$ of these isolates was penicillin resistant [23]. Resistance of S.pneumoniae to the third-generation cephalosporin CTX was increasing in the above areas due to the acquisition of an additional 19 amino acid substitutions in penicillin binding protein $2 \mathrm{~b}$ (PBP2b) and PBP2x through genome recombination events [23]. Furthermore, the pbp2b gene of S.pneumoniae has very low affinity for cephalosporins and inactivation of this gene seems not to be working on the CTX [24] thus cause the high rate of non-susceptible CTX but low rate of PNSP in our study.

Macrolide resistance rates of pneumococcal isolates vary greatly throughout the world however the pneumococci resistance rate to erythromycin was $72.7 \%$ in Asia, with the highest rate in China (96.4\%) as reported by ANSORP [25]. It is noteworthy that pneumococci harboring both $\operatorname{erm}(\mathrm{B})$ and $m e f(\mathrm{E})$ genes continue to be reported, with a global prevalence of $16.4 \%$ among macrolide-resistant pneumococcal isolates [26]. Overall in this study, 94.6 and $62 \%$ of the macrolide-resistant pneumococci were positive for erm(B) and $m e f(\mathrm{~A} / \mathrm{E})$, respectively. The present study also showed that $78.6 \%$ of the Taiwan ${ }^{19 \mathrm{~F}}-14$ clone harbored dual positive genes, while only $11.1 \%$ of other STs harbored both genes which is consistent with a previous report that $\operatorname{erm}(\mathrm{B})$ and mef genes have been related to the Taiwan ${ }^{19 F}-14$ clone [265]. As a result of the insertion of erm(B) into conjugative transposons of the Tn916 family, most of pneumococcal isolates carried erm(B) genes are also resistant to tetracycline, typically carrying tet(M) [22]. In our study, most of Taiwan ${ }^{19 \mathrm{~F}}-14$ isolates harbored $\operatorname{erm}(\mathrm{B}), \operatorname{mef}(\mathrm{A} / \mathrm{E})$ and $\operatorname{tet}(\mathrm{M})$ genes, while only $41.2 \%$ of other isolates expressed these three genes. These findings suggest that the widespread of highly resistant CC271 maybe driven by the selective pressure of the antibiotic use, which poses a serious public health concern for increasing treatment failure with the empirical usage of macrolide antibiotics.

Two serotypes (19F and 19A) were the most prevalent serotypes (81.1\% of these pneumococcal isolates) in our study, which was consistent with a report from children with AOM from Suzhou (80.5\%) [20]. Reports for pneumococcal isolates identified from other specimens such as respiratory and nasopharynx revealed that 19F, $14,23 \mathrm{~F}, 6 \mathrm{~B}$ and $19 \mathrm{~A}$ were the most common serotypes [6]. In our study, the serotype coverage rate of PCV7 and PCV13 was 73.0 and $94.6 \%$, respectively. Together with the reports from Suzhou and Shenzhen, China [5, 6], these results support that the increasing coverage of PCV13 was mainly because of the high occurrence of serotype 19A and suggest that expanded use of PCV13 in China, may significantly reduce the prevalence of pneumococcal diseases (especially the invasive pneumococcal diseases) resulting from high prevalence of serotype 19A, although serotype replacement always remains a concern.

Using the eBURST analysis both ST271 and ST320 are members of CC271 which accounts for $75.7 \%$ of the pneumococcal isolates in this study. CC271 is a multidrug resistant pneumococcal clone (Taiwan ${ }^{19 F}$-14) which has been described internationally [27]. The clone described in this study is classified as multi drug resistant as it is resistant to penicillin, erythromycin and tetracycline which also carry the Tn2010 genetic element encoded on the $\operatorname{erm}(\mathrm{B}), \operatorname{mef}(\mathrm{E})$ and tet $(\mathrm{M})$ genes [28]. Although not examined in the present study, previous studies have shown the increase of CC271 from 14.3\% in 1997 in Beijing, China which rose to $92.0 \%$ in 2010 [29]. CC271 has also previously been described as the most prevalent clone causing invasive pneumococcal disease [30]. This clone appears to have become successful due to a number of factors, for example increasing international movements, selective pressure due to antibiotic use [29], this clone is now distributed globally and is 
widespread having been described in Colombia, Spain, USA and China [31-34]. Increased resistance to antibacterial medications continue to pose great challenges for treating the pneumococcal diseases.

Recent evidence has revealed that the pneumococcal serotype 19A/ST320 clone, driven from Taiwan ${ }^{19 F}-14$ clone (ST236), switched serotype in response to the selective pressures of the immunization of PCV7 and has become prevalent in many countries, within Asia including China [33, 34]. This clone afflicted Chinese children before the introduction of PCV7 in 2008 [27] and that serotype 19A/ST320 has become resistant to multiple antibiotics [34]. Notably, serotype 19A/ST320 was also found in our study, and most of the serotype 19A/ST320 isolates were multidrug-resistant, and harbored erm(B), $m e f(\mathrm{~A} / \mathrm{E})$ and $\operatorname{tet}(\mathrm{M})$ genes. These findings suggest that antibiotic prescribing patterns in China may play a significant role in the switching serotype from 19F to 19A and their homogeneous genetic background. The high prevalence of serotype 19A/ST320 clone suggests that PCV13 should be included into the Chinese Expanded Program on Immunizations, which could further reduce the burden of pneumococcal diseases.

Vaccine candidates such as $p s p A$, a protein-based vaccine candidate has been demonstrated to be independent of capsular serotypes [35]. This high identical capacity made $p s p A$ as a good vaccine candidate to improve the protecting efficacy of the pneumococcal isolates compared with the current usage of serotype-based vaccines, since $p s p A$ could avoid the serotype replacement which has been observed in the current usage of pneumococcal vaccines [36]. As serogroups 6 and 19 seem to be associated with $p s p A$ families, this suggests that vaccines covering the $p s p A$ family might be a better option than the current pneumococcal vaccines which are dependent on the presence of certain capsules. In line with a previous study [35], the current results confirmed that $86.5 \%$ of the pneumococci harbored $p s p A$ gene and was associated with serotypes $6 \mathrm{~B}, 15 \mathrm{~B} / \mathrm{C}, 14,23 \mathrm{~A}, 19 \mathrm{~A}$ and $19 \mathrm{~F}$, further supporting the consideration of $p s p A$ as a leading candidate for future vaccine development.

Pilus islet has recently been implicated in its virulence for assisting the pneumococci with adherence to host tissue [37] and its capacity of initiating mucosal damage and triggering mucosal inflammation means the pilus islet is able to invade the tissue [37]. A prior study emphasized the high prevalence of the pilus islet among capsular serotypes included in PCV7 such as 19F [38], and the re-emergence of pilus islet among non-vaccine serotype of pneumococcal isolates also has been reported recently [39]. Both the PI-1 ( $r l r A)$ and PI-2 ( $\operatorname{sip} A)$ genes have previously been associated with the Taiwan ${ }^{19 F}$-14 clone (CC271), we describe a genetic relatedness to CC271 together with serotypes $19 \mathrm{~F}$ and 19A and found the strains also carried the $\operatorname{erm}(\mathrm{B}), \operatorname{mef}(\mathrm{A} / \mathrm{E})$ and tet $(\mathrm{M})$ genes. This suggests there may be a clinical relevance between the presence of these genes and AOM in Chinese children. Our work suggests that there is a clonal relationship between the virulence gene, serotype and presence of the pilus islet within CC271 [40].

There were several limitations within the present study. An obvious limitation of the study is the retrospective design and the small sample size, which may limit the generalizability of our study results.. Second, this study mainly focused on children with AOM obtained by tympanocentesis and these isolates may not be representative of the whole spectrum of otitis media, however, the PCR detection of the whole genetic background of pneumococcal isolates including serotype, MLST, antibiotic determinants and virulence factors represent important strengths of the study design. The third one was that we didn't use controls in the PCRs. However, the $100 \mathrm{bp}$ plus DNA ladder marker was used for molecular weight reference as the references described to make sure we get the right results.

\section{Conclusions}

In conclusion, the emergence of multidrug-resistant S.pneumoniae 19A/ST320 harboring multiple antibiotic resistance genes and virulence genes is both concerning and a great challenge to treat the pneumococcal diseases which warrants the continued monitoring of pneumococcal diseases in Chinese children. The high prevalence of international multidrug-resistant clone (Taiwan ${ }^{19 \mathrm{~F}}-14$ ) in western China necessitates the continued dedication to expand PCV13 immunization in national vaccination programs along with efforts to curb and control the overuse of antibiotics in Chinese children.

\section{Abbreviations \\ ANSORP: Asian Network for Surveillance of Resistant Pathogens; AOM: Acute otitis media; CC: Clonal complex; CTX: Cefotaxime; H.influenzae: Haemophilus influenzae; MLST: Multilocus sequence typing; PCV: Pneumococcal conjugate vaccine; PNSP: Penicillin-nonsusceptible S.pneumoniae; PRSP: Penicillin resistant S.pneumoniae; S.pneumoniae: Streptococcus pneumoniae; STs: Sequence types \\ Acknowledgements \\ Not applicable. \\ Funding \\ This manuscript was funded by Guangxi Medical and Health Self-funding Project (No Z2014379, No Z2016531, Z20170509, Z20180022), Guangxi Nature Science Foundation (No. 2015GXSFBA139129), and Liuzhou Science and Technology Bureau Project (No 2014 J030422, 2017BD20201, 2018BJ10502, 2018BJ10504). The funders had no role in study design, data collection and analysis, decision to publish, or preparation of the manuscript.}

Availability of data and materials

We declare that the data supporting the conclusions of this article are available from the corresponding author on reasonable request. 


\section{Authors' contributions}

J F and $L L$ designed the study and drafted an outline. S X, Z L, N L and P Q participated in data analysis, JF draft of initial manuscript, $L L, Z L$ and $N L$ participated in diagnosed and collected the data, $E M$ and $X Y$ revised the manuscript and all of authors approved the final content off this manuscript.

\section{Ethics approval and consent to participate}

This study was approved by the Institutional Review Board of Liuzhou Maternity and Child Healthcare Hospital (No 2017003). A written informed consent was obtained from parents or legal guardians on behalf of the children involved in the study for collection of information and samples. The Ethics Committee also permitted the authors to use the patients records to write this article.

\section{Consent for publication}

Not applicable.

\section{Competing interests}

The authors declare that they have no competing interests.

\section{Publisher's Note}

Springer Nature remains neutral with regard to jurisdictional claims in published maps and institutional affiliations.

\section{Author details}

'Department of Laboratory, Liuzhou Maternity and Child Healthcare Hospital, Liuzhou, China. ${ }^{2}$ School of Public Health, Guangdong Pharmaceutical University, 283\# Jianghai Dadao, Haizhu District, Guangzhou 510310, China. ${ }^{3}$ Department of Pediatric, Liuzhou Maternity and Child Health Care Hospital, Liuzhou, Guangxi, China. ${ }^{4}$ Department of Otolaryngology, Liuzhou Maternity and Child Health Care Hospital, Liuzhou, Guangxi, China. ${ }^{5}$ Children's Hospital of Michigan, Detroit, MI, USA. 'Wayne State University School of Medicine, Detroit, MI, USA.

\section{Received: 23 January 2018 Accepted: 8 February 2019}

Published online: 15 February 2019

\section{References}

1. Pichichero ME. Ten-year study of the stringently defined otitis-prone child in Rochester. NY Pediatr Infect Dis J. 2016 Sep;35(9):1033-9.

2. Ngo CC, Massa HM, Thornton RB, Cripps AW. Predominant Bacteria detected from the middle ear fluid of children experiencing otitis media: a systematic review. PLoS One. 2016;11(3):e0150949.

3. Coker TR, Chan LS, Newberry SJ, Limbos MA, Suttorp MJ, Shekelle PG, et al Diagnosis, microbial epidemiology, and antibiotic treatment of acute otitis media in children: a systematic review. JAMA. 2010;304(19):2161-9.

4. Shekelle PG, Takata G, Newberry SJ, Coker T, Limbos MA, Chan LS, et al. Management of Acute Otitis Media: update. Evid Rep Technol Assess (Full Rep). 2010 Nov:(198):1-426.

5. Ma X, Zhao R, Ma Z, Yao K, Yu S, Zheng Y, et al. Serotype distribution and antimicrobial resistance of Streptococcus pneumoniae isolates causing invasive diseases from Shenzhen Children's hospital. PLoS One. 2013;8(6): e67507.

6. Geng $Q$, Zhang $T$, Ding $Y$, Tao $Y$, Lin $Y$, Wang $Y$, et al. Molecular characterization and antimicrobial susceptibility of Streptococcus pneumoniae isolated from children hospitalized with respiratory infections in Suzhou. China PLoS One. 2014;9(4):e93752.

7. Kim SH, Song JH, Chung DR, Thamlikitkul V, Yang Y, Wang H, ANSORP Study Group, et al. Changing trends in antimicrobial resistance and serotypes of Streptococcus pneumoniae isolates in Asian countries: an Asian network for surveillance of resistant pathogens (ANSORP) study. Antimicrob Agents Chemother. 2012;56(3):1418-26.

8. Rodgers GL, Arguedas A, Cohen R, Dagan R. Global serotype distribution among Streptococcus pneumoniae isolates causing otitis media in children: potential implications for pneumococcal conjugate vaccines. Vaccine. 2009; 27(29):3802-10.

9. Cohen R, Varon E, Doit C, Schlemmer C, Romain O, Thollot F, et al. A 13year survey of pneumococcal nasopharyngeal carriage in children with acute otitis media following PCV7 and PCV13 implementation. Vaccine. 2015;33(39):5118-26.
10. Balsells E, Guillot L, Nair H, Kyaw MH. Serotype distribution of Streptococcus pneumoniae causing invasive disease in children in the post-PCV era: a systematic review and meta-analysis. PLoS One. 2017;12(5):e0177113.

11. Weil-Olivier C, van der Linden M, de Schutter I, Dagan R, Mantovani L. Prevention of pneumococcal diseases in the post-seven valent vaccine era: a European perspective. BMC Infect Dis. 2012;12:207.

12. Hu J, Sun X, Huang Z, Wagner AL, Carlson B, Yang J, et al. Streptococcus pneumoniae and Haemophilus influenzae type $b$ carriage in Chinese children aged 12-18 months in Shanghai, China: a cross-sectional study. BMC Infect Dis. 2016;16:149.

13. Hu S, Shi Q, Chen Cl, Caldwell R, Wang B, Du L, et al. Estimated public health impact of nationwide vaccination of infants with 7-valent pneumococcal conjugate vaccine (PCV7) in China. Int J Infect Dis. 2014;26:116-22.

14. Clinical and Laboratory Standards Institute. Performance standards for antimicrobial susceptibility testing: twenty-sixth informational supplement M100-S19. Wayne, PA, USA: CLSI; 2016.

15. Ahn JG, Choi SY, Kim DS, Kim KH. Enhanced detection and serotyping of Streptococcus pneumoniae using multiplex polymerase chain reaction. Korean J Pediatr. 2012;55(11):424-9.

16. Malhotra-Kumar S, Lammens C, Piessens J, Goossens H. Multiplex PCR for simultaneous detection of macrolide and tetracycline resistance determinants in streptococci. Antimicrob Agents Chemother. 2005;49(11): 4798-800.

17. Shakrin NN, Masri SN, Taib NM, Nordin SA, Jamal F, Desa MN. Genotypic characterization of Malaysian human isolates of Streptococcus pneumoniae from carriage and clinical sources. Comp Immunol Microbiol Infect Dis. 2014;37(5-6):347-54

18. Enright MC, Spratt BG. A multilocus sequence typing scheme for Streptococcus pneumoniae: identification of clones associated with serious invasive disease. Microbiology. 1998;144(Pt 11):3049-60.

19. Scally M, Schuenzel EL, Stouthamer R, Nunney L. Multilocus sequence type system for the plant pathogen Xylella fastidiosa and relative contributions of recombination and point mutation to clonal diversity. Appl Environ Microbiol. 2005;71(12):8491-9.

20. Ding Y, Geng Q, Tao Y, Lin Y, Wang Y, Black S, et al. Etiology and epidemiology of children with acute otitis media and spontaneous otorrhea in Suzhou. China Pediatr Infect Dis J. 2015;34(5):e102-6.

21. Zhao C, Li Z, Zhang F, Zhang X, Ji P, Zeng J, et al. Serotype distribution and antibiotic resistance of Streptococcus pneumoniae isolates from 17 Chinese cities from 2011 to 2016. BMC Infect Dis. 2017;17(1):804.

22. Li QH, Yao KH, Yu SJ, Ma X, He MM, Shi W, et al. Spread of multidrugresistant clonal complex 271 of serotype $19 F$ Streptococcus pneumoniae in Beijing, China: characterization of serotype 19F. Epidemiol Infect. 2013; 141(12):2492-6.

23. Ip M, Ang I, Liyanapathirana V, Ma H, Lai R. Genetic analyses of penicillin binding protein determinants in multidrug-resistant Streptococcus pneumoniae serogroup 19 CC320/271 clone with high-level resistance to third-generation cephalosporins. Antimicrob Agents Chemother. 2015;59(7): 4040-5.

24. Coffey TJ, Daniels M, McDougal LK, Dowson CG, Tenover FC, Spratt BG. Genetic analysis of clinical isolates of Streptococcus pneumoniae with highlevel resistance to expanded-spectrum cephalosporins. Antimicrob Agents Chemother. 1995 Jun;39(6):1306-13.

25. Del Grosso M, Northwood JG, Farrell DJ, Pantosti A. The macrolide resistance genes erm $(B)$ and mef(E) are carried by Tn2010 in dual-gene Streptococcus pneumoniae isolates belonging to clonal complex CC271. Antimicrob Agents Chemother. 2007;51(11):4184-6.

26. Li Y, Tomita H, LV Y, Liu J, Xue F, Zheng B, et al. Molecular characterization of erm(B)- and mef(E)-mediated erythromycin-resistant Streptococcus pneumoniae in China and complete DNA sequence of Tn2010. J Appl Microbiol. 2011;110(1):254-65.

27. Qian J, Yao K, Xue L, Xie G, Zheng Y, Wang C, et al. Diversity of pneumococcal surface protein a (PspA) and relation to sequence typing in Streptococcus pneumoniae causing invasive disease in Chinese children. Eur J Clin Microbiol Infect Dis. 2012;31(3):217-23.

28. Ramos V, Parra EL, Duarte C, Moreno J. Characterization of Streptococcus pneumoniae invasive serotype 19A isolates recovered in Colombia. Vaccine. 2014;32(7):755-8.

29. Ardanuy C, Rolo D, Fenoll A, Tarrago D, Calatayud L, Liñares J. Emergence of a multidrug-resistant clone (ST320) among invasive serotype 19A pneumococci in Spain. J Antimicrob Chemother. 2009;64(3):507-10. 
30. Isturiz R, Sings HL, Hilton B, Arguedas A, Reinert RR, Jodar L. Streptococcus pneumoniae serotype 19A: worldwide epidemiology. Expert Rev Vaccines. 2017;16(10):1007-27.

31. Shin J, Baek JY, Kim SH, Song JH, Ko KS. Predominance of ST320 among Streptococcus pneumoniae serotype 19A isolates from 10 Asian countries. J Antimicrob Chemother. 2011;66(5):1001-4.

32. Lyu S, Yao KH, Dong F, Xu BP, Liu G, Wang Q, et al. Vaccine Serotypes of Streptococcus pneumoniae with High-level Antibiotic Resistance Isolated More Frequently Seven Years After the Licensure of PCV7 in Beijing. Pediatr Infect Dis J. 2016;35(3):316-21.

33. Calatayud L, Ardanuy C, Cercenado E, Fenoll A, Bouza E, Pallares R, et al. Serotypes, clones, and mechanisms of resistance of erythromycin-resistant Streptococcus pneumoniae isolates collected in Spain. Antimicrob Agents Chemother. 2007;51(9):3240-6.

34. Rice LB. Tn916 family conjugative transposons and dissemination of antimicrobial resistance determinants. Antimicrob Agents Chemother. 1998; 42(8):1871-7.

35. Yatim MM, Masri SN, Desa MN, Taib NM, Nordin SA, Jamal F. Determination of phenotypes and pneumococcal surface protein A family types of Streptococcus pneumoniae from Malaysian healthy children. J Microbiol Immunol Infect. 2013 Jun;46(3):180-6.

36. Hotomi M, Togawa A, Kono M, Ikeda Y, Takei S, Hollingshead SK, et al. PspA family distribution, antimicrobial resistance and serotype of Streptococcus pneumoniae isolated from upper respiratory tract infections in Japan. PLoS One. 2013;8(3)::58124.

37. Golden AR, Rosenthal M, Fultz B, Nichol KA, Adam HJ, Gilmour MW, et al. Characterization of MDR and XDR Streptococcus pneumoniae in Canada, 2007-13. J Antimicrob Chemother. 2015;70(8):2199-202.

38. Zähner D, Gudlavalleti A, Stephens DS. Increase in pilus islet 2-encoded pil among Streptococcus pneumoniae isolates, Atlanta, Georgia, USA. Emerg Infect Dis. 2010;16(6):955-62.

39. Wierzbowski AK, Karlowsky JA, Adam HJ, Nichol KA, Hoban DJ. Zhanel GG; Canadian antimicrobial resistance Alliance. Evolution and molecular characterization of macrolide-resistant Streptococcus pneumoniae in Canada between 1998 and 2008. J Antimicrob Chemother. 2014;69(1):59-66

40. Moschioni M, Donati C, Muzzi A, Masignani V, Censini S, Hanage WP, et al. Streptococcus pneumoniae contains 3 rlrA pilus variants that are clonally related. J Infect Dis. 2008;197(6):888-96.

Ready to submit your research? Choose BMC and benefit from:

- fast, convenient online submission

- thorough peer review by experienced researchers in your field

- rapid publication on acceptance

- support for research data, including large and complex data types

- gold Open Access which fosters wider collaboration and increased citations

- maximum visibility for your research: over $100 \mathrm{M}$ website views per year

At $\mathrm{BMC}$, research is always in progress.

Learn more biomedcentral.com/submissions 